\title{
Immature teratoma of kidney in a 5-month-old child
}

\author{
Adhikari RC ${ }^{1}$, Sayami G ${ }^{1}$ \\ ${ }^{I}$ Department of Pathology, Tribhuvan University Teaching Hospital, Maharajgunj, Kathmandu, Nepal
}

\section{Keywords: \\ Infant; \\ Immature teratoma; \\ Renal}

\begin{abstract}
We report a rare case of immature renal teratoma in a 5-month-old female infant. The patient presented with abdominal mass, which was found to arise from the left kidney. The preoperative diagnosis of Wilms' tumor was based on clinical and imaging findings. The patient was managed with nephrectomy and had normal recovery. The histopathological examination of nephrectomy specimen revealed grade 2 immature teratoma.
\end{abstract}

\section{INTRODUCTION}

Teratomas arise from pluripotent cells and can differentiate along one or more germ lines. Most teratomas of infancy and childhood arise in sacro-coccygeal region. ${ }^{1,2}$ Other sites are ovary, testis, mediastinum, brain and retroperitoneum. ${ }^{3,4}$ The kidney represents an exceedingly rare site of extragonadal germ cell tumor. Only 16 cases of intrarenal teratoma in children have been reported 5 and only few of them reported as immature..$^{5-7}$ The main primary childhood renal neoplasms are nephroblastoma, mesoblastic nephroma, clear cell sarcoma and rhabdoid tumor. The teratoid nephroblastoma can be confused with a teratoma because of the presence of heterologus tissues.

\section{CASE REPORT}

A 5-month-old female admitted with the complaints of abdominal distention since last 2 months. She was born at term with a weight of $2.5 \mathrm{Kg}$. There was no history of

Correspondence:

Dr. Ram Chandra Adhikari, MD

Associate professor, Department of Pathology, Tribhuvan University

Teaching Hospital, Maharajgunj, Kathmandu, Nepal

Email:rcadhikari@hotmail.com other systemic problems. On admission, she weighed 4.6 $\mathrm{Kg}$ with features of grade II malnutrition. On palpation, a soft mass of about $11 \times 8 \mathrm{~cm}$ was palpable on the left side of the abdomen, which was crossing the midline.

Hemogram, urinalysis, renal function tests and chest X-ray were within normal limits. Serum alpha feto protein was elevated $(716 \mathrm{ng} / \mathrm{ml})$ and $\beta$ HCG was normal $(<1 \mathrm{mIU} / \mathrm{ml})$. Ultrasonography of abdomen revealed a complex mass on the left side of the abdomen crossing the midline. CT scan of abdomen showed $10.6 \times 10.4 \times 8.2 \mathrm{~cm}$ well-defined complex cystic-solid mass in the abdominal cavity occupying whole of the left hemi-abdomen and crossing the midline to right. Calcified nodule was seen in the upper part of the lesion. The mass is arising from the upper pole of the left kidney. Right kidney was normal.

A provisional diagnosis of Wilms' tumor was made. Laparatomy was done and left kidney along with tumor was excised. 


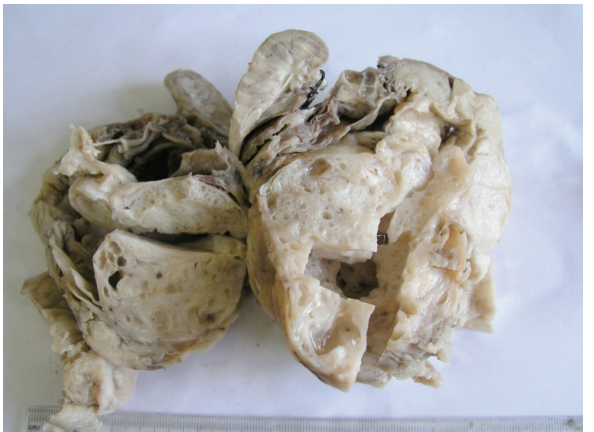

Figure 1: Gross appearance, Immature teratoma kidney. Solid and cystic areas are shown. Normal kidney is evident in the upper region.

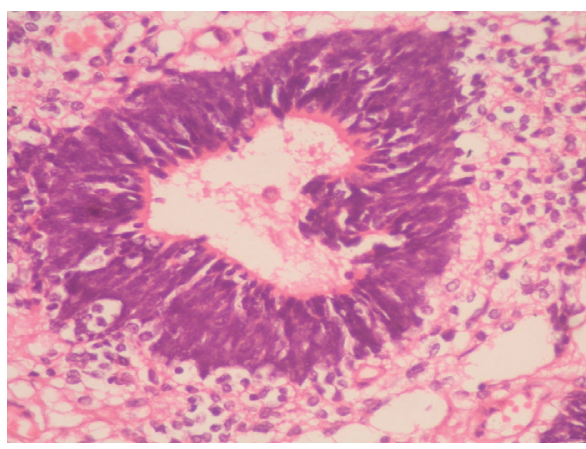

Figure 3: Neuroepithelial tubule (HE stain, X400).

\section{Histopathological findings}

Left nephrectomy specimen along with the tumor mass was received. The kidney measured $6 \times 4 \times 1.5 \mathrm{~cm}$ and the mass originating from and involving the upper pole of kidney measured $10.5 \times 10 \times 8 \mathrm{~cm}$. The mass showed well defined borders, gray in color with soft to firm consistency. On sectioning, the tumor showed solid areas and multiple cystic spaces of variable sizes with the largest cystic space measuring $1 \mathrm{x} 0.8 \mathrm{~cm}$ (fig. 1).

Microscopically, the cystic spaces were lined by columnar epithelium, mucinous epithelium and stratified squamous epithelium. Nests of squamous cells, bronchial structures (fig. 2) with glands and cartilage, smooth muscle and bone were evident. In addition, there were neuroglial tissue and melanin containing cells. There were foci of immature neuroepithelial tissue disposed in the background of glial tissue. The neuroepithelial tissue consisted of tubules (fig. 3 ) and rosettes, lined by columnar cells with hyperchromatic nucleus. These foci constituted approximately 2 low power fields per slide. No blastemal foci are present. With this, the diagnosis of immature teratoma, grade 2 was made.

\section{DISCUSSION}

The most common childhood renal neoplasm presenting as an abdominal mass is Wilms' tumor. Renal teratomas are exceptionally rare. The most common germ cell

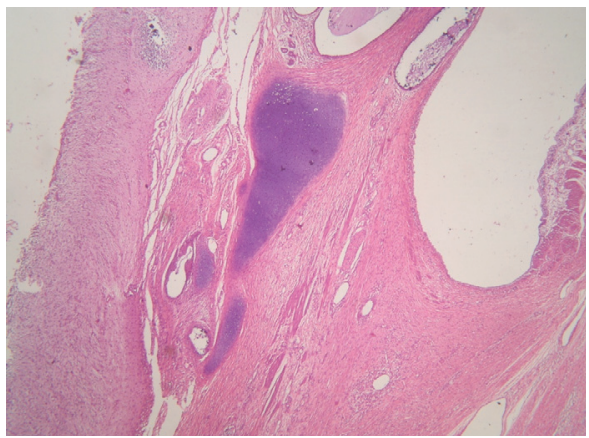

Figure 2: Bronchial structure (HE stain, X400).

tumor which occurs during the first year of life is sacrococcygeal teratoma. ${ }^{8}$ Teratomas contain elements derived from the embryonic ecto-, meso- and endodermal layers. In mature teratomas, skin with dermal appendages, bronchial structures with bronchial glands and cartilage, neuroglial tissue and teeth are commonly presented and regarded as evidence of organogenesis. ${ }^{9}$ Mukhopadhyay $\mathrm{M}$ et al reported duplication of caecum and appendix as evidence of organogenesis in renal teratoma. ${ }^{6}$ Primary carcinoid tumors in a mature teratoma of the kidney have also been reported. ${ }^{10,11}$ Neuroepithelial tissue and other immature components are present in immature teratoma.

In this case, the pre-operative diagnosis of Wilms' tumor was based on clinical and CT findings. During pathological examination of renal teratoma, the diagnosis of teratoid Wilm's tumor must be excluded. ${ }^{12}$ Wilms' tumor originates from mesodermal metanephrogenic blastema and can consist of both ectodermal and mesodermal tissue giving a similar appearance to a teratoma. ${ }^{13}$

To diagnose a renal teratoma, the primary tumor should be unequivocally of renal origin and the tumor should exhibit unequivocal heterotopic organogenesis. ${ }^{14}$ In our case, there were no blastemal element and both criteria proposed by Beck with 14 were fulfilled.

The clinical presentations of renal teratoma are abdominal mass, abdominal pain, vomiting, constipation and hematuria. ${ }^{15}$ Our case presented with abdominal mass alone.

Pediatric patient with pure immature teratomas can effectively be treated with a complete surgical excision alone..$^{5}$ In cases of recurrent disease, a combination of surgical resection followed by chemotherapy recommended. ${ }^{5}$

\section{CONCLUSION}

Although renal teratoma is rare, it is necessary to consider this entity as one of the differential diagnosis of paediatric renal mass and to distinguish it from teratoid Wilms' tumor. 


\section{REFERENCES}

1. Berry CL, Keeling J, Hilton C. Teratomata in infancy and childhood: A review of 91 cases. J Pathol 1969;98:241-52.

2. Mahour GH. Woolley MM, Trevedi SN, Landing BH. Teratomas in infancy and childhood: Experience with 81 cases. Surgery $1974 ; 76: 309-18$

3. Harms D, Janig U. Immature teratomas of childhood. Report of 21 cases. Pathol Res Pract 1985;179:388-400.

4. Dehner LP. Intrarenal teratoma occurring in infancy: report of a case with discussion of extragonadal germ cell tumors in infancy. J Pediatr Surg 1973;8: 369-78.

5. Evans K, Rogers T, Garrett-Cox R. A rare case of intrarenal teratoma in a 6-month-old male. Pediatr Blood Cancer 2010;55:1207-9.

6. Mukhopadhyay M, Shukla RM, Mandal KC, Mukhopadhyay B. Renal teratoma with duplication of cecum and appendix. J Pediatr Surg 2010;45:255-8.

7. Yaqoob N, Ahmed Z, Jafri N, Muzaffar S, Hasan SH. Renal teratoma: a rare entity. J Pak Med Assoc 2003;53:492-3.

8. Aubert J, Casamayou J. Intrarenal teratoma: Study of a case in an infant. J Urol Nephrol 1978;84:539-44.
9. Govender D, Nteene LM, Chetty R, Hadley GP. Mature rena teratoma and synchronous malignant neuroepithelial tumor of the ipsilateral adrenal gland. J Clin Pathol 2001;54:253-4.

10. Kim J, Suh K. Primary carcinoid tumor in a mature teratoma of the kidney: Ultrasonographic and computed tomographic findings. J Ultrasound Med 2004;23:433-7.

11. Yoo J, Park S, Jung Lee H, Jin Kang S, Kee Kim B. Primary carcinoid tumor arising in a mature teratoma of the kidney: a case report and review of literature. Arch Pathol Lab Med 2002;126:979-81.

12. Cecchetto G, Alaggio R, Scarzello G et al. Teratoid Wilm's tumor: report of unilateral case. J pediatr Surg 2003;38:259-61.

13. Mochizuki K, Ohno Y, Tokai Y et al. Congenital intrarenal teratoma arising from a horseshoe kidney. J Pediatr Surg 2006;41:1313-15.

14. Beckwith JB. Wilm's tumor and other renal tumors of childhood: a selective review from the National Wilm's Tumor Study Pathology Center. Hum Pathol 1983;14:481-92.

15. Aubert J, Casmayou J, Denis $\mathrm{P}$ et al. Intrarenal renal teratoma in a newborn child. Eur Urol 1978;4:306-8. 